\title{
Single-Cell Molecular and Cellular Architecture of the Mouse Neurohypophysis
}

\author{
Qiyu Chen, ${ }^{1}$ Dena Leshkowitz, ${ }^{2}$ Janna Blechman, ${ }^{1}$ and ${ }^{\circledR}$ Gil Levkowitz ${ }^{1}$
}

https://doi.org/10.1523/ENEURO.0345-19.2019

${ }^{1}$ Department of Molecular Cell Biology, Weizmann Institute of Science, Rehovot 7610001 , Israel and ${ }^{2}$ Bioinformatics Unit, Life Sciences Core Facilities, Weizmann Institute of Science, Rehovot 7610001, Israel

\begin{abstract}
The neurohypophysis $(\mathrm{NH})$, located at the posterior lobe of the pituitary, is a major neuroendocrine tissue, which mediates osmotic balance, blood pressure, reproduction, and lactation by means of releasing the neurohormones oxytocin (OXT) and arginine-vasopressin (AVP) from the brain into the peripheral blood circulation. The major cellular components of the $\mathrm{NH}$ are hypothalamic axonal termini, fenestrated endothelia and pituicytes, the resident astroglia. However, despite the physiological importance of the $\mathrm{NH}$, the exact molecular signature defining neurohypophyseal cell types and in particular the pituicytes, remains unclear. Using single-cell RNA sequencing (scRNA-Seq), we captured seven distinct cell types in the NH and intermediate lobe (IL) of adult male mouse. We revealed novel pituicyte markers showing higher specificity than previously reported. Bioinformatics analysis demonstrated that pituicyte is an astrocytic cell type whose transcriptome resembles that of tanycyte. Single molecule in situ hybridization revealed spatial organization of the major cell types implying intercellular communications. We present a comprehensive molecular and cellular characterization of neurohypophyseal cell types serving as a valuable resource for further functional research.
\end{abstract}

Key words: neuroendocrine; neurohypophysis; oxytocin; pituicyte; pituitary; tanycyte

\section{Significance Statement}

The neurohypophysis $(\mathrm{NH})$ is a major neuroendocrine interface, which allows the brain to regulate the function of peripheral organs in response to specific physiologic demands. Despite its importance, a comprehensive molecular description of cell identities in the $\mathrm{NH}$ is still lacking. Utilizing single-cell RNA sequencing (scRNA-Seq) technology, we identified the transcriptomes of five major neurohypophyseal cell types in the adult male mice and mapped the spatial distribution of selected cell types in situ. We revealed an unexpected cellular heterogeneity of the $\mathrm{NH}$ and provide novel molecular markers for neurohypophyseal cell types with higher specificity than previously reported.

\section{Introduction}

The pituitary, also dubbed the hypophysis, is the master endocrine gland that is localized at the base of the hypothalamus in all vertebrate species. It is composed of the adenohypophysis $(\mathrm{AH})$ and the neurohypophysis $(\mathrm{NH})$, also known as the anterior and posterior pituitary, respec-

\footnotetext{
Received August 28, 2019; accepted November 25, 2019; First published January 8, 2020.

The authors declare no competing financial interests.

Author contributions: Q.C. and G.L. designed research; Q.C. and J.B. performed research; Q.C., D.L., and G.L. analyzed data; Q.C. and G.L. wrote the paper.
}

tively. The mammalian pituitary consists of an additional anatomically discernable tissue, the intermediate lobe (IL), which is located between the $\mathrm{NH}$ and $\mathrm{AH}$. However, the IL is not as distinguished in the pituitary of human and some non-mammalian vertebrates, including zebrafish (Gutnick et al., 2011; Norris et al., 2013; Wircer et al., 2016; Larkin and Ansorge, 2017). The hypothalamo-neurohypophyseal sys-

G.L. is supported by the Israel Science Foundation Grant 1511/16, MinervaWeizmann program, Adelis Metabolic Research Fund, Yeda-Sela Center for Basic Research (in the frame of the Weizmann Institute), the Nella and Leon Benoziyo Center for Neurologic Diseases, Richard F. Goodman Yale/Weizmann Exchange Program, and Estate of Emile Mimran. 
tem (HNS) encompasses hypothalamic magnocellular neurons residing in the paraventricular nucleus (PVN) and supraoptic nucleus (SON) and project their axons into the $\mathrm{NH}$. Thus, two neuropeptides, oxytocin (OXT) and argininevasopressin (AVP), are produced in magnocellular neurons, transported along neurohypophyseal-projecting axons and released into the general blood circulation through the neurohypophyseal capillary plexus (Murphy et al., 2012). Circulating OXT and AVP neurohormones affect the physiologic function of peripheral organs such as the kidney, mammary gland and the uterus. Specifically, AVP regulates osmotic balance and blood pressure (Wircer et al., 2016; Donadon et al., 2018; Olazábal, 2018), while OXT is mainly known due to its effects on reproduction organs (Lee et al., 2009).

Unlike the $\mathrm{AH}$, which serves as a hormone-secreting gland, the $\mathrm{NH}$ is a neural tissue, which serves as a neuroendocrine interface between AVP and OXT axonal projections and the permeable capillary network of fenestrated endothelia (Robinson and Verbalis, 2003). This neurovascular interface also contains the pituicytes, specialized neurohypophyseal astroglia, which occupy $\sim 50 \%$ of the neurohypophyseal total volume (Bucy, 1930; Pow et al., 1989). Pituicytes engulf HNS axonal swellings and their terminal buttons and are in close contact with the basal laminar and vascular endothelia (Robinson and Verbalis, 2003; Miyata, 2017). Based on their dynamic morphologic plasticity during lactation and in response to chronic dehydration, it has been suggested that the pituicytes mediate neurohormones passage through the fenestrated capillaries serving as a physical gateway between the axons and the perivascular space (Hatton, 1988; Wittkowski, 1998). Recently, we reported that during development, pituicyte-derived factors regulate the decision of zebrafish $\mathrm{NH}$ vasculature to adopt a permeable endothelial fate instead of forming a BBB (Anbalagan et al., 2018). The early definition of pituicytes was based on histochemical staining with silver carbonate and hematoxylin and eosin (Bucy, 1930; Liss, 1958; Dellmann and Sikora, 1981). Thus, different subtypes of pituicytes have been defined by their fibrous, ependymal (with cilia or microvilli), oncocytic morphologies or by ultrastructure of organelle contents, such as dark and pale pituicytes due to high/low density contents of cytoplasmic matrix and organelles and granular pituicytes containing numerous cytosegregosome type dense bodies (Seyama et al., 1980; Wittkowski, 1986; Anbalagan et al., 2018). How-

Acknowledgements: We thank Yael Kuperman for her help in neurohypophysis dissection, Hagit Dafni for providing C57BL6 mice for dissociation protocol optimization, Stefan Jung for providing the Cx3cr1:GFP mice and Shalev Itzkovitz for the smFISH probes, Amrutha Swaminathan and Ludmila Gordon for their valuable comments on the text and figures, and Hanjie Li for his advices on cluster annotation. G.L. is an incumbent of the Elias Sourasky Professorial Chair.

Correspondence should be addressed to Gil Levkowitz at gil.levkowitz@weizmann.ac.il.

https://doi.org/10.1523/ENEURO.0345-19.2019

Copyright (C) 2020 Chen et al.

This is an open-access article distributed under the terms of the Creative Commons Attribution 4.0 International license, which permits unrestricted use, distribution and reproduction in any medium provided that the original work is properly attributed. ever, there is very little knowledge of pituicyte-specific genes. Consequently, mammalian pituicytes have been so far labeled with astroglial markers, such as apolipoprotein $\mathrm{E}$ (APOE), GFAP, S100 $\beta$, vimentin (VIM), and connexin43 (Cx43/GJA1), all of which are general astrocytic markers, which are also expressed in other cell types (Cocchia, 1981; Suess and Pliška, 1981; Boyles et al., 1985; Marin et al., 1989; Yamamoto and Nagy, 1993). Moreover, defining and visualizing pituicytes by coexpression of the above genes is not informative as these markers only partially overlap (Wei et al., 2009). Hence, the exact definition of pituicyte cell type and/or subtype remains ambiguous. Finally, other neurohypophyseal cell types might not have been detected in published bulk neurohypophyseal transcriptomic data (Hindmarch et al., 2006).

The recent technological revolution enables high-resolution studies for transcriptome patterns in heterogeneous cell populations. Single-cell RNA sequencing (scRNA-Seq) allows dissecting cell types that are previously hidden due to identical histology, same genetic marker and adjacent location within a complex tissue (Potter, 2018). This technology enables hundreds and thousands of single cells being processed at once, therefore delivers high-throughput, and highly efficient analysis of cell heterogeneity. In this study, we used scRNA-Seq to unravel the cell heterogeneity of the $\mathrm{NH}$. Seven major cell types in the $\mathrm{NH}$ and IL of adult male mouse were identified. We present a comprehensive view of the molecular landscape as well as spatial organization of $\mathrm{NH}$ and $\mathrm{IL}$ cell types, hence providing valuable resources for studying their specific cellular and physiologic functions.

\section{Materials and Methods}

\section{Experimental design}

Three-month-old male C57/BL6 and Cx3cr1-GFP mice (Jung et al., 2000) were used in this study. All experimental procedures were approved by the Weizmann Institute's Institutional Animal Care and Use Committee (IACUC).

\section{Single-cell dissociation}

Two independent groups of five C57/BL6 mice were sacrificed by decapitation and the $\mathrm{NH}$ were dissected and collected into ice-cold $1 \mathrm{ml}$ of magnesium-free and calcium-free HBS-/- buffer (20 mM HEPES-buffered saline, $145 \mathrm{mM} \mathrm{NaCl}, 5.4 \mathrm{mM} \mathrm{KCl}$, and $20 \mathrm{mM}$ glucose, $\mathrm{pH}$ 7.2) (Dieck, 1999). NH tissues were then transferred to ice-cold PBS containing magnesium and calcium ( $\mathrm{Hy}$ Clone, GE Healthcare), treated with $50 \mathrm{ng} / \mu$ l Liberase TM (Roche) for $12 \mathrm{~min}$ at $37^{\circ} \mathrm{C}$, and further dissociated by incubating in HBS-/- buffer containing $0.15 \mathrm{mg} / \mathrm{ml}$ Papain (Sigma) and $10 \mathrm{U} / \mathrm{ml}$ DNase I (Invitrogen) for $8 \mathrm{~min}$ at $37^{\circ} \mathrm{C}$. The reaction was stopped by adding heatinactivated fetal bovine serum (HI-FBS; HyClone) to reach final concentration of $5 \%$. To obtain single-cell resuspension, the loosened tissues were collected and passed through a $40-\mu \mathrm{m}$ nylon mesh in $800-\mu$ l resuspension buffer [Leibovitz L-15 with $0.3 \mathrm{mM}$ glutamine (Gibco, Thermal Fisher), $0.5 \%$ of penicillin streptomycin solution 
(Gibco, Thermo Fisher), 1\% HI-FBS, 0.04\% BSA]. Cell number, survival rate, clarity, and singularity were checked by Trypan Blue staining followed by hemocytometer counting.

\section{scRNA-Seq}

scRNA-Seq was performed with 10x Genomics Chromium Single Cell kit version 2. Two independent samples, each containing $600-800$ cells $/ \mathrm{ml}$, which had $\sim 70 \%$ survival rate and very few debris were used to form droplets containing single cell and barcoded-beads. The targeted recovery was 4000 cells per sample. The subsequent cDNA synthesis and library preparations were conducted according to the manufacturer's protocol (10x Genomics). Two libraries were then indexed and pooled for sequencing using a NextSeq 500 High Output v2 kit (75 cycles; Illumina) according to the manufacturer's instructions. Four lanes were used with R1 26 cycles and R2 58 cycles.

\section{Data and software availability}

The accession number for the NH single-cell transcriptome reported in this paper is Gene Expression Omnibus (GEO; www.ncbi.nlm.nih.gov/geo): GSE135704.

\section{Statistical analyses}

Sequences data were demultiplexed using Illumina bcl2fastq. Each of the samples was analyzed by Cellranger (version 2.0.0), run with the option -force-cells = 1500 and using the $10 \mathrm{X}$ prebuilt $\mathrm{mm} 10$ reference database version 1.2.0. The outputs from CellRanger were further analyzed using the Seurat package V2.3 (Butler et al., 2018) and R 3.5. Using Seurat, we performed gene filtering (gene must appear in three cells of a sample) and merging of the cells of both samples to one set. Cell filtering was based on the number of genes per cell (must be between 400 and 5000), the number of UMI counts per cell (between 1000 and 10,000), and the percentage of mitochondria genes lower than 0.25 percentage. Eleven clusters were created with 900 variable genes and 11 principal components (PCs). The cluster names were replaced with the cell type identity based on the differentially expressed genes (marker genes).

\section{Gene set enrichment analysis}

To determine whether known biological functions or gene sets are overrepresented (enriched) in an experimentally-derived gene list, an overrepresentation analysis (ORA) (Boyle et al., 2004) was employed. The gene set associated with a cell type, which was downloaded from PanglaoDB database (Franzen et al., 2019) were compared to the differentially expressed pituicyte markers filtered with criteria of average_logFC $\geq 1$ and padj $\leq 0.05$. To test for overrepresentation of successes in the sample, the hypergeometric $p$ value was calculated using $R$ function phyper with lower tail= false as the probability of randomly drawing $\mathrm{k}$ or more successes from the population in $\mathrm{n}$ total draws (Kachitvichyanukul and Schmeiser, 1985). The FDR was achieved by adjusting the $p$ value using Benjamini and Hochberg (Benjamini and Hochberg, 1995). To further illustrate the above finding specific differentially expressed pituicyte markers were compared with filtering criteria of average $\log F C \geq 1$ and padj $\leq 0.05$ to published scRNA-Seq gene lists of astrocytes, and tanycytes i.e., PanglaoDB and other studies (Campbell et al., 2017; Chen et al., 2017; Saunders et al., 2018; Zeisel et al., 2018; Franzen et al., 2019).

\section{Wholemount in situ hybridization (WISH) and immunostaining}

Three-month-old C57BL6 mice were perfused and fixed by $2 \%$ PFA for 10 min and fixed in 4\% PFA on ice for $20 \mathrm{~min}$ in the dark. WISH was performed as described in (Machluf and Levkowitz, 2011; Wircer et al., 2017) with prolonged proteinase $\mathrm{K}$ treatment of $45 \mathrm{~min}$. Tissues were postfixed in 4\% PFA for $20 \mathrm{~min}$ at room temperature and washed $3 \times 15$ min PBS-Tx (Triton X-100; 0.3\%). Subsequent immunostaining of WISH samples was performed following re-blocking in blocking buffer ( $10 \%$ lamb serum, $0.3 \%$ Triton $\mathrm{X}-100,1 \%$ DMSO in PBS) for $1 \mathrm{~h}$. Primary antibody staining was performed at $4^{\circ} \mathrm{C}$ overnight. After $3 \times 30-$ min PBS-Tx wash, the samples were incubated with 1:200 secondary antibody at $4^{\circ} \mathrm{C}$ overnight, followed by $3 \times 30-$ min PBS-Tx wash and mounting in $75 \%$ glycerol. Imaging of WISH samples was performed using Zeiss LSM 800 confocal microscope with oil immersion $40 \times$ objective. Whole z-stack maximum intensity projections and cell number quantification of specific cell populations were generated by Fiji-ImageJ software.

\section{Cryotomy and fluorescent in situ hybridization (smFISH)}

C57BL6/Cx3cr1-GFP transgenic mice were sacrificed by decapitation. The whole pituitary was quickly dissected and fixed in $1 \%$ PFA containing $30 \%$ sucrose overnight at $4{ }^{\circ} \mathrm{C}$. The fixed tissue was then washed and equilibrated in half Tissue-Tek O.C.T Compound (Sakura) and half $60 \%$ sucrose (final $30 \%$ ) mixture before positioned inside a plastic mold with only O.C.T compound and frozen by burying in dry ice powder. After the whole block turned opaque, it was stored at $-80^{\circ} \mathrm{C}$ in a sealed plastic bag in the dark. Before cryotomy, the embedded O.C.T block was first equilibrated inside the Cryostat machine (Leica) to $-25^{\circ} \mathrm{C}$ for 30 min followed by cryosectioning $(7 \mu \mathrm{m})$ and slice collection on $22 \times 22-\mathrm{mm}$ glass coverslips \#1 (Thermo Scientific Menzel), precoated with $0.01 \%$ L-lysine (Sigma), and stored at $-80^{\circ} \mathrm{C}$ in a Parafilm sealed six-well plate in the dark for up to a month before further digestion and prehybridization steps. smFISH was conducted as described in ( $\mathrm{Ji}$ and van Oudenaarden, 2012) with the exception that the formamide concentration was increased to $30 \%$ for prehybridization and washing. Tissue sections were mounted on Prolong Gold antifade mountant (Thermo Fisher) and images were captured using a wide-field fluorescent microscope (Nikon Eclipse Ti-E) with a cooled CCD camera equipped with oil immersion $60 \times$ objective.

\section{Vibratome sections}

Pituitary from $\mathrm{C} \times 3 \mathrm{cr} 1$-GFP mouse was dissected on ice and fixed in $4 \%$ PFA overnight at $4^{\circ} \mathrm{C}$. After washing, the pituitary was embedded in 3\% Nobel Agarose (BD Biosciences) on ice; $50-\mu \mathrm{m}$ coronal sections were cut using 
A

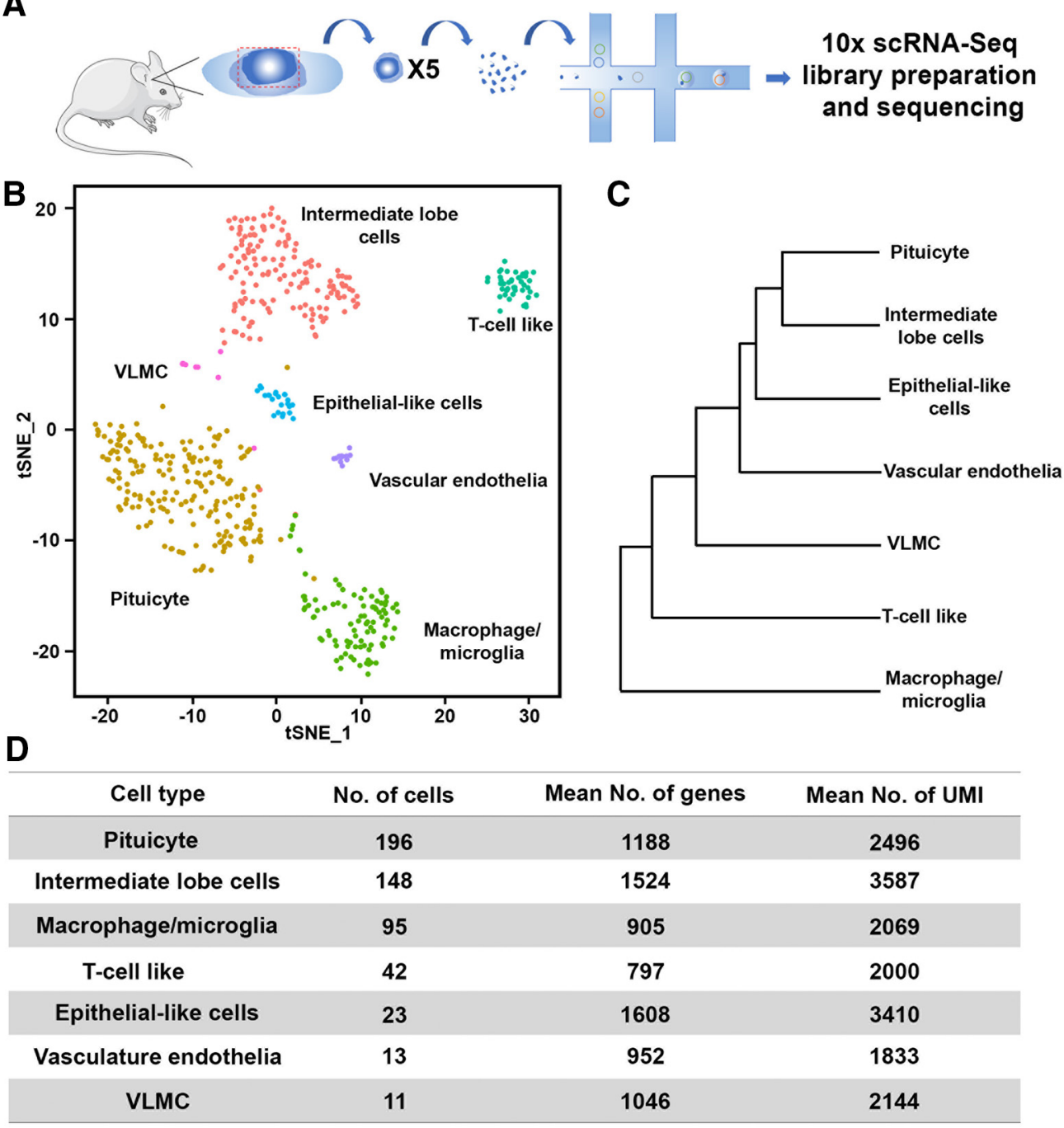

Figure 1. Single-cell RNA-Seq reveals seven cell types of dissected mouse NH. $\boldsymbol{A}$, Schematic representation of the scRNA-Seq procedure. Neurohypophyseal tissues were dissected from five C57BL6 adult male mice and pooled. Two independent pools were separately subjected to single-cell dissociation, single-cell capturing, and library preparation using the 10x chromium platform. The two libraries were then indexed and combined for sequencing using NextSeq 500 High Output v2 kit (75 cycles). B, The two libraries were pooled and mapped on the tSNE plot, showing cell clusters of IL cells, T-cell like, VLMC, epithelial like cells, vascular endothelia macrophage/microglia, and pituicyte. Each dot represents one cell, and cells with the same color belong to one cell type. C, Dendrogram showing the distance matrix from the PCA space of the average cell among the seven cell types. The length of the path between each two cell types indicates the relativeness between them. $\boldsymbol{D}$, A table summarizing the number of cells, average number of genes and UMls found in each cell type.

a Leica VT1000 S vibrating blade microtome (Leica) and then mounted with Aqua-Poly/Mount (Polysciences). The sections were then imaged using a Zeiss LSM 800 confocal microscope.

\section{Results}

\section{scRNA-Seq revealed seven cell types in the NH and} IL

The pituitary is located within a bony structure of the mouse skull, dubbed sella turcica, allowing accurate surgical isolation of this tissue. In particular, the medially located $\mathrm{NH}$ can be readily observed owing to its conspicuous white color, due to the high density of neurohypophyseal axons and pituicytes. We took advantage of these anatomic features to dissect neurohypophyseal tissue from three-month-old C57/BL6 male mice and thereafter performed scRNA-Seq analysis. Notably, the isolated tissue contained residual tissue from the adjacent intermediate pituitary lobe (IL), hence we took into consideration that our $\mathrm{NH}$ tissue preparation will contain some IL cells (Fig. 1A; Extended Data Fig. 1-1A).

We collected two pools of dissected neurohypophyseal tissue, each has been derived from five mice. Single cells from the dissociated tissue were thereafter captured using the 10x chromium gel beads in a droplet, followed by independent library preparation for each pool. The two sets of libraries were indexed and sequenced together (Fig. 1A). The low variation between the pools was de- 
tected in the PC analysis (PCA) plot containing the two first PCs and in the tSNE plot using Seurat R package (Butler et al., 2018). The two data sets were pooled and cell clusters were built using the 900 most variable genes using FindClusters function in Seurat package using 11 PCs with resolution 1.0 and analyzed together to create the tSNE plot (Fig. 1B; Extended Data 1-1B). The normalized differentially expressed genes of each cluster (Extended Data Figs. 1-2, 1-3) were used to identify seven major cell types, which were designated based on expression of published marker genes and following comparisons to existing single-cell database (Fig. 1B). Thus, we compared our gene lists to the mouse brain atlas from the Linnarsson Lab (Zeisel et al., 2018), the PanglaoDB database (Franzen et al., 2019), the cell type function from Allen Brain Atlas (http://celltypes.brain-map.org/), mouse vascular and vascular associated cell single-cell database (He et al., 2018; Vanlandewijck et al., 2018), and the DropViz web tool (Saunders et al., 2018). We also compared our data to published scRNA-Seq of anatomically adjacent tissues, such as the hypothalamus and the median eminence (Campbell et al., 2017; Chen et al., 2017; Extended Data Figs. 1-4, 1-5). The identified NH cell types were labeled as: pituicyte, macrophage/microglia, vascular endothelia, T-cell like and vascular and leptomeningeal cells (VLMCs). As expected, due to the nature of the dissection procedure mentioned above, we also identified IL cells. The latter was identified by comparing to recently published whole mouse pituitary single-cell transcriptomes (Cheung et al., 2018; Ho et al., 2018; Mayran et al., 2018). To determine the relativeness of the clustered cell types, we used the BuildClusterTree function in Seurat R package to generated dendrogram, representing a phylogenetic tree relating the "average" cell from each identity class (Fig. 1C). The number of cells, as well as mean number of genes and average number unique molecular identifiers (UMIs) representing each of the designated cell types are shown in Figure 1D. Notably, the cell number does not necessarily reflect the compositional proportion in the tissue but probably randomized sampling in singlecell capturing, varied resilience of different cell types to dissociation procedure and cell type-specific RNA stability.

Following the identification of $\mathrm{NH}$ and IL cell types, we searched for sets of genetic markers characterizing each cell type. We generated a heatmap showing cluster analysis of the top twenty differentially expressed genes representing the transcriptomic profile of the various $\mathrm{NH}$ and IL cell types and then selected three feature genes, which represent each cell type (Fig. 2). These included known markers for VLMC cells (Ogn, Lum, and Dcn), fenestrated vascular endothelia (Emcn, Flt1, and Plvap), T-cell like (Ms4a4b and $C d 3 d$ ), and macrophage/microglia (Ctss, C1qa, and Cx3cr1) (Stan et al., 1999; Liu et al., 2001; Kindt et al., 2007; Marques et al., 2016). In the case of three of the identified cell types, epithelial-like cells, pituicytes, and IL cells, there was no published database and therefore they were designated based on the top differentially expressed markers. Thus, the epithelial cell markers $\mathrm{Krt18}, \mathrm{Krt8}$, and $\mathrm{Clu}$ were top-ranked in the so-called epithelial-like cells, and the melanotrope markers Pomc and Pcsk2 were used to designate IL cells. To define the pituicyte cell type we first used Vegfa and Gja1, which were previously associated with this cell type (Yamamoto and Nagy, 1993; Furube et al., 2014). Next, we performed an unbiased bioinformatics analysis by comparing our pituicyte transcriptome to PanglaoDB, a public database for exploration of mouse and human scRNA-Seq data (Franzen et al., 2019). We employed ORA, which is a widely used approach to determine if known biological functions or gene sets are overrepresented in an experimentally-derived gene list (Boyle et al., 2004). Our unbiased comparison of the pituicyte to all PanglaoDB gene sets revealed that the pituicyte cluster is highly enriched in tanycyte (FDR $=1.20 \mathrm{E}-21)$ followed by astrocytes (FDR = 1.18E-07) and Bergmann glia (FDR = 5.63E-06; Extended Data Fig. 1-4). To further illustrate the above finding, we compared the specific differentially expressed pituicyte markers with other published scRNASeq data of tanycytes (40\% shared markers) and astrocytes (12\% shared markers) in addition to PanglaoDB (Campbell et al., 2017; Chen et al., 2017; Saunders et al., 2018; Zeisel et al., 2018; Franzen et al., 2019; Extended Data Fig. 1-5). Therefore, the unique differentially expressed featured genes we assigned for these cell types are novel markers. Thus, the novel markers Lcn2, Cyp2f2, and Krt18 represented epithelial-like cells; Pcsk2, Scg2, and Chga marked IL cells, and finally, Col25a1, Scn7a, and Srebf1 were selected as pituicyte panel of markers (Fig. 2). The specificity of the selected marker genes is exemplified in Figure 3 in which a featured gene from each cluster is highlighted in the tSNE plot showing distinct distributions of different cell types (Fig. 3A). A violin plot showing the normalized log-transformed singlecell expression of selected featured genes in the different cell types is shown in Figure $3 B$.

\section{Novel pituicyte genes display higher specificity than commonly used markers}

We report five selected differentially expressed genes, Srebf1, Rax, Scn7a, Adm, Col25a1, and Col13a1, which showed robust expression in the majority of pituicyte population (Fig. 4A). Four of these genes, Srebf1, Rax, $A d m$, and Col25a1 were robustly expressed in the pituicyte population. Srebf1 displayed residual expression in a small number of epithelial-like cells but was not differentially expressed in this cluster (Fig. 4A; Extended Data Figs. 1-2 and 1-3).

We noticed that the novel pituicyte genes revealed by scRNA-Seq displayed higher specificity than previously published pituicytes markers (Cocchia, 1981; Suess and Pliška, 1981; Boyles et al., 1985; Marin et al., 1989; Yamamoto and Nagy, 1993). Thus, violin plots of our scRNA-Seq indicated that two commonly used pituicyte markers Gfap and $S 100 \beta$ displayed low normalized logtransformed expressions in the pituicyte population. Furthermore, Apoe, which is often used as pituicyte and astrocyte marker displayed low cell-type specificity, as it was detected in all neurohypophyseal types except for T-cell like. The other three reported pituicyte markers 

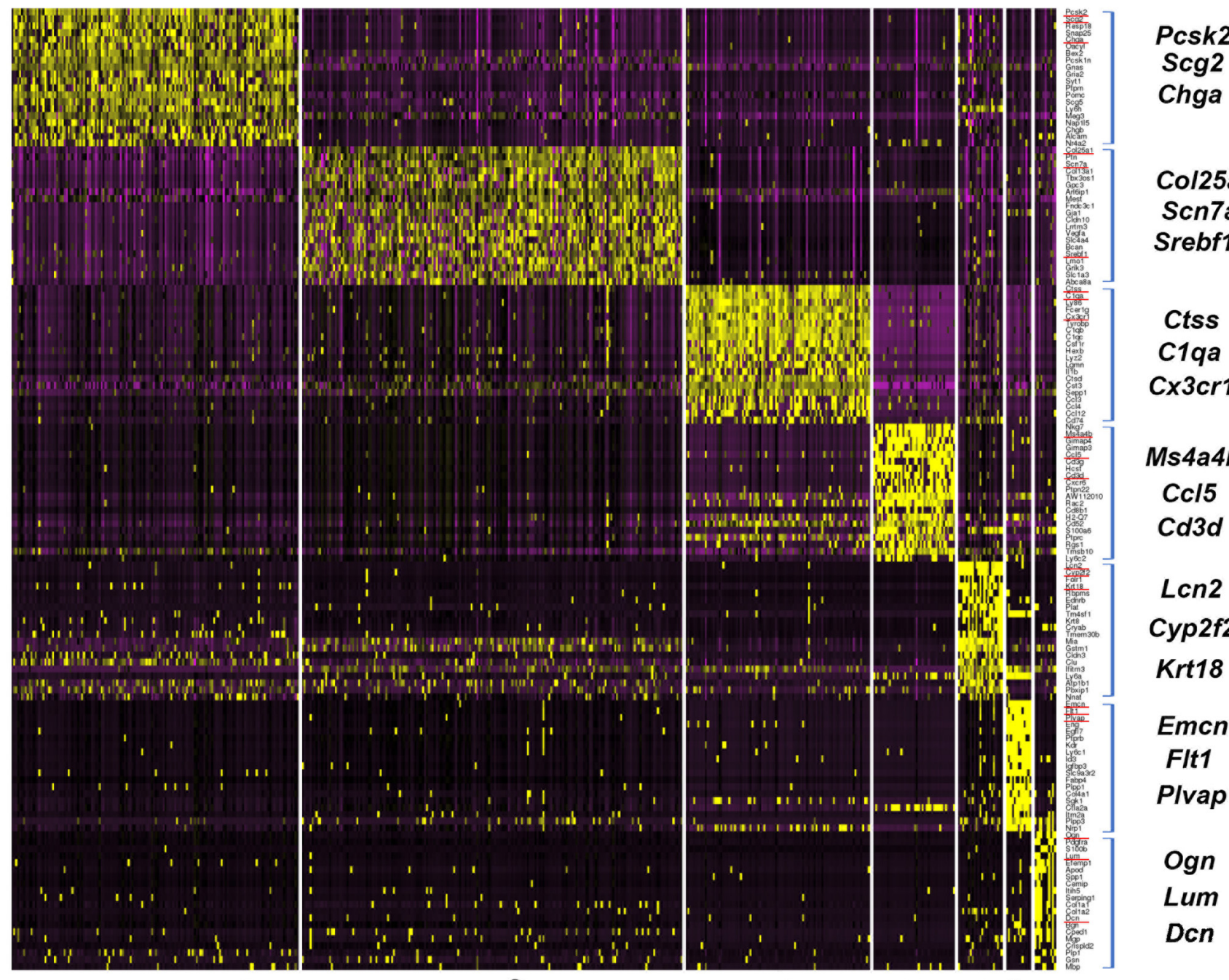

Scg2

Chga

Col25a1

Scn7a

Srebf1

Ctss

C1qa

CX3cr1
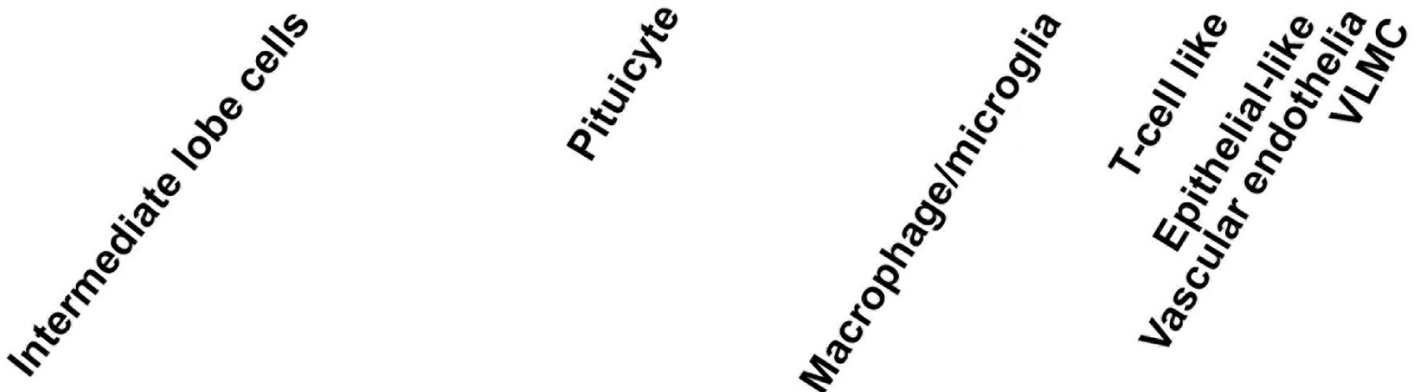

Ms4a4b

Cc/5

Cd3d

Len2

Cyp2f2

Krt18

Emcn

Flt1

Plvap

Ogn

Lum

Dcn

Figure 2. Heatmap of differentially expressed genes in neurohypophyseal and IL cell clusters. Heatmap showing scaled gene expression of the top twenty genes (square brackets) representing each of the seven cell types found in the $\mathrm{NH}$ and IL. Each column display gene expression of an individual cell and genes are listed in the rows. Selected marker genes are underlined in red and enlarged on the side.

Gja1/Cx43, Vegfa, and Vim (Marin et al., 1989; Yamamoto and Nagy, 1993; Furube et al., 2014) displayed higher normalized pituicyte expression and were somewhat more specific than Apoe (Fig. 4B). Notably, although Vim displayed some expression in the pituicyte cells, it did not pass the differentially expressed criteria in the pituicyte cluster when compared to other cell types (Extended Data Figs. 1-2 and 1-3).

We next examined whether the novel pituicyte markers identified by scRNA-Seq are expressed in the mouse $\mathrm{NH}$ by in situ hybridization. The selected pituicyte marker Col25a1 (Fig. 4A) with robust normalized expression (adjusted $p=8.38 \mathrm{E}-82$, average $\ln$ fold change $=1.67$ ) was subjected to wholemount mRNA in situ hybridization, followed by immunostaining with an antibody against the previously published pituicyte marker Vim. This analysis showed that Vim immunoreactivity is detected in a subset of Col25a1-positive cells (Fig. 5; Extended Data Fig. 5-1; Movie 1). This analysis was in agreement with our scRNASeq bioinformatic analysis (Fig. 4), suggesting that some 

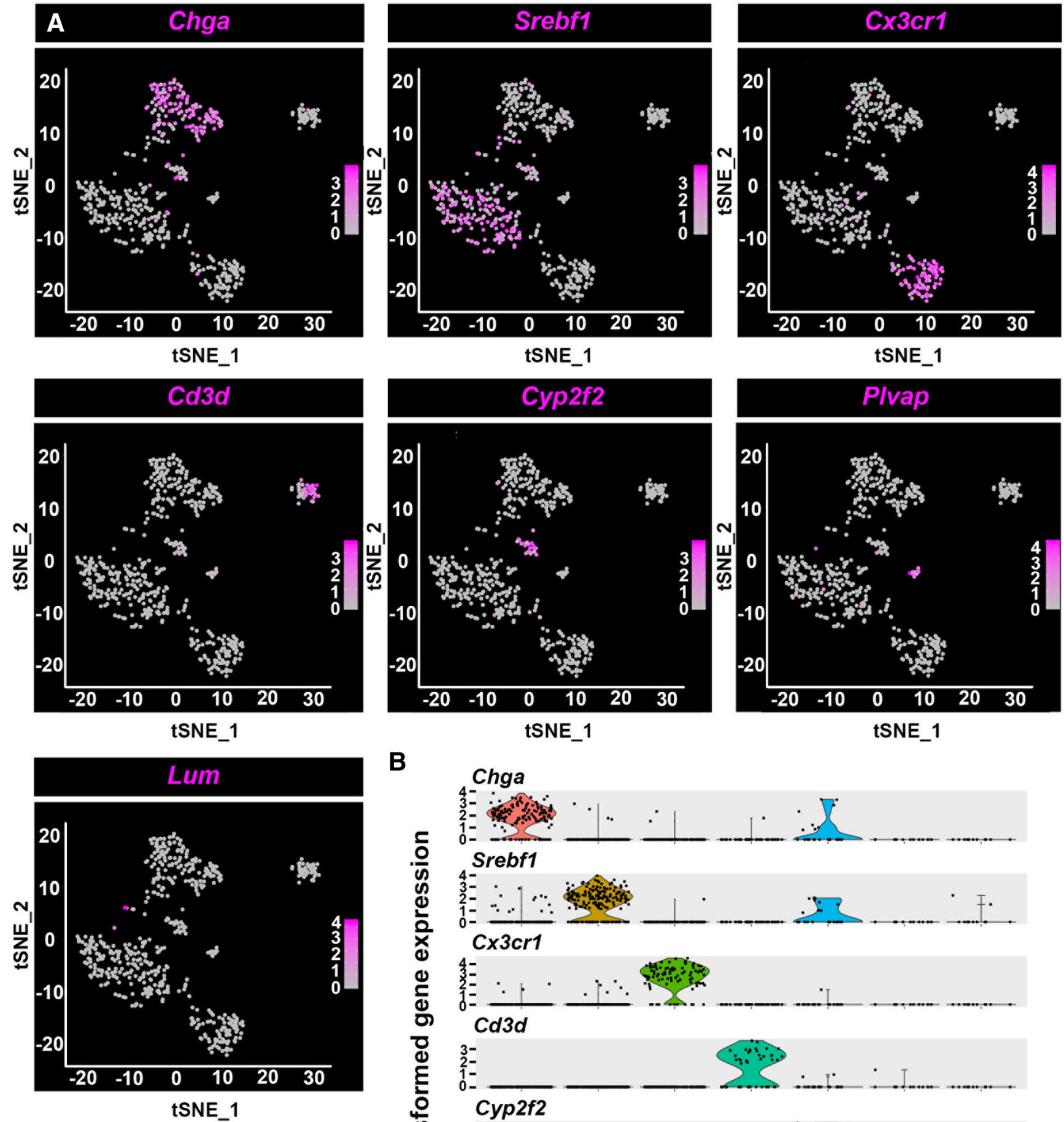

B

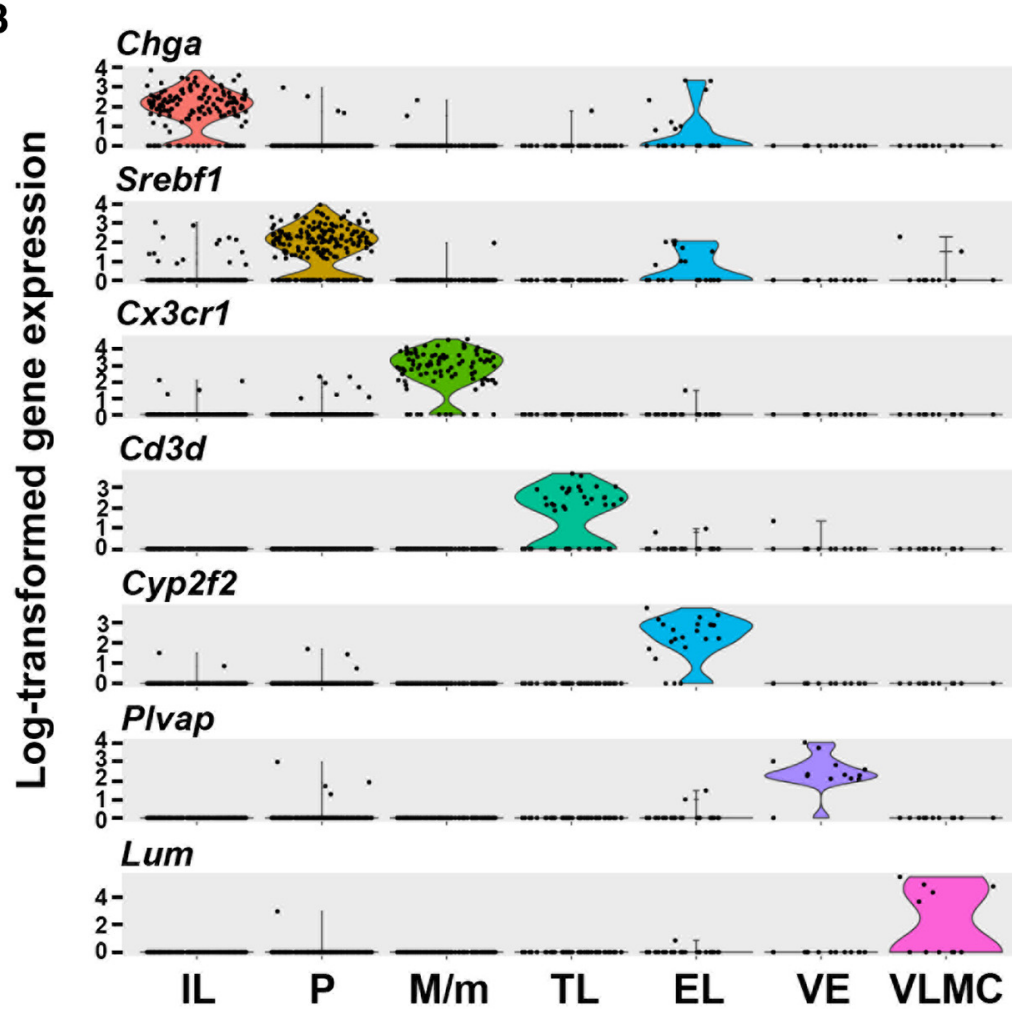

Figure 3. Featured genes representing the landscape of the seven neurohypophyseal and IL cell types. $\boldsymbol{A}$, Distribution of featured genes from 
continued

each cell type embedded in tSNE plots. The gene expression scale was color-coded with high expression level in deep blue, low expression in gray. B, Violin plots displaying normalized log-transformed expressions of each featured gene distributed across all the seven clusters. EL, epithelial-like cells; M/m, macrophage/microglia; P, pituicyte; TL, T-cell like; VE, vascular endothelia.

A

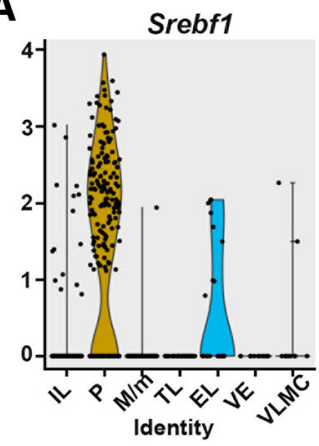

Adm

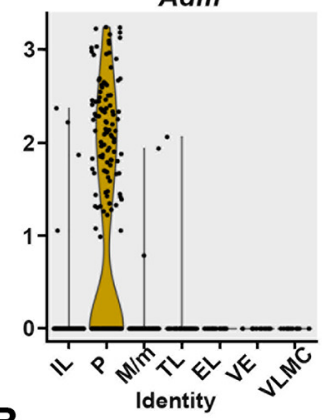

B

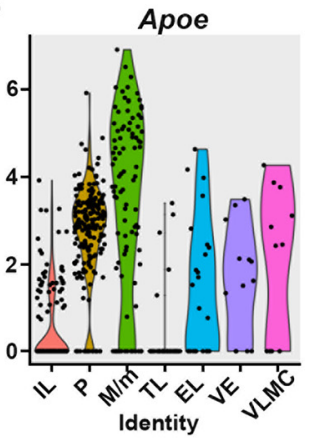

S100b

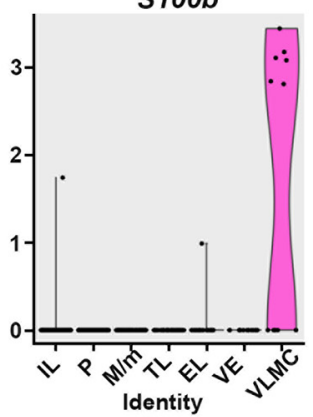

$\operatorname{Rax}$

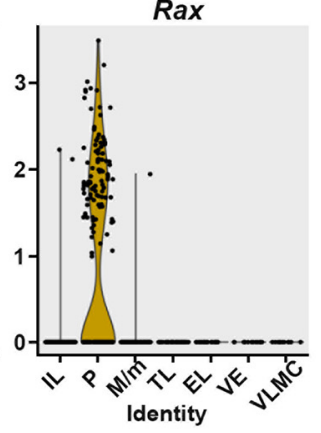

Col25a1

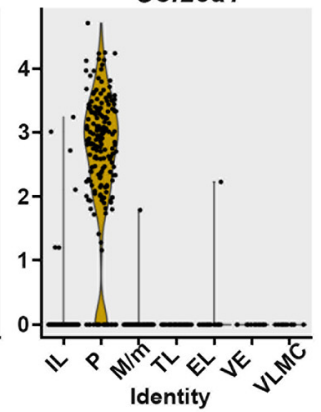

Vim

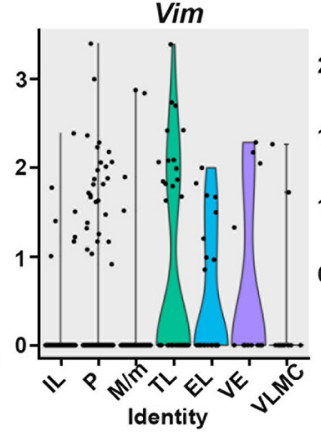

Gja1

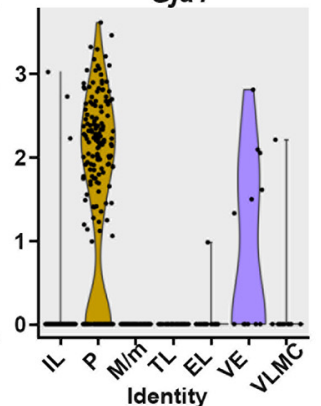

Scn7a

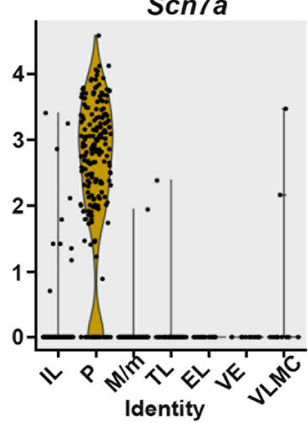

Col13a1

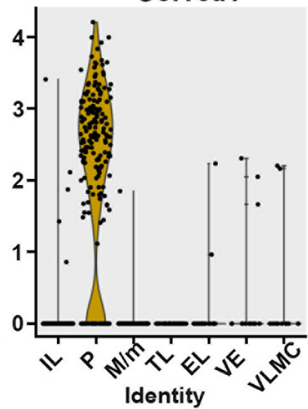

Grap

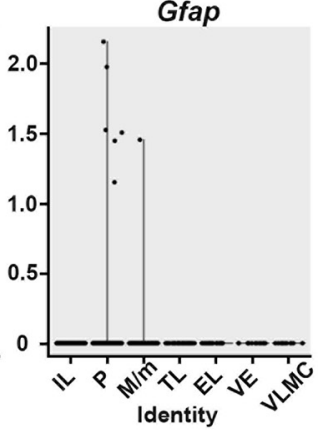

Vegfa

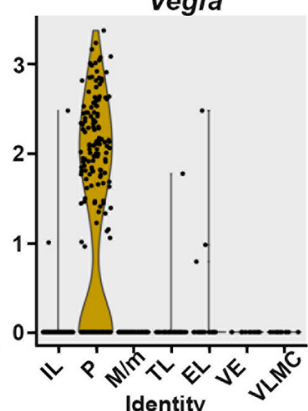

Figure 4. Novel pituicyte markers show higher specificity and robustness compared to previously used markers. $\boldsymbol{A}$, Violin plots displaying expression distributions of novel pituicyte marker genes in seven pituitary cell types seven clusters. Srebf1, Rax, Scn7a, Adm, Col25a1, and Col13a1 were selected from this single-cell RNA-Seq data and mapped onto the violin plots. The $y$-axis represents the normalized log-transformed expression of respective genes. Each dot represents a cell and the shape of the violin represents the proportion of cells being enriched compared to the rest of cells in a given cluster. B, Previously published pituicyte markers Apoe, Vim, Gfap, $S 100 \beta$, Gja1 (Cx43), and Vegfa were mapped onto the violin plots within the seven identified cell types. EL, epithelial-like cells; M/m, macrophage/microglia; P, pituicyte; TL, T-cell like; VE, vascular endothelia. 

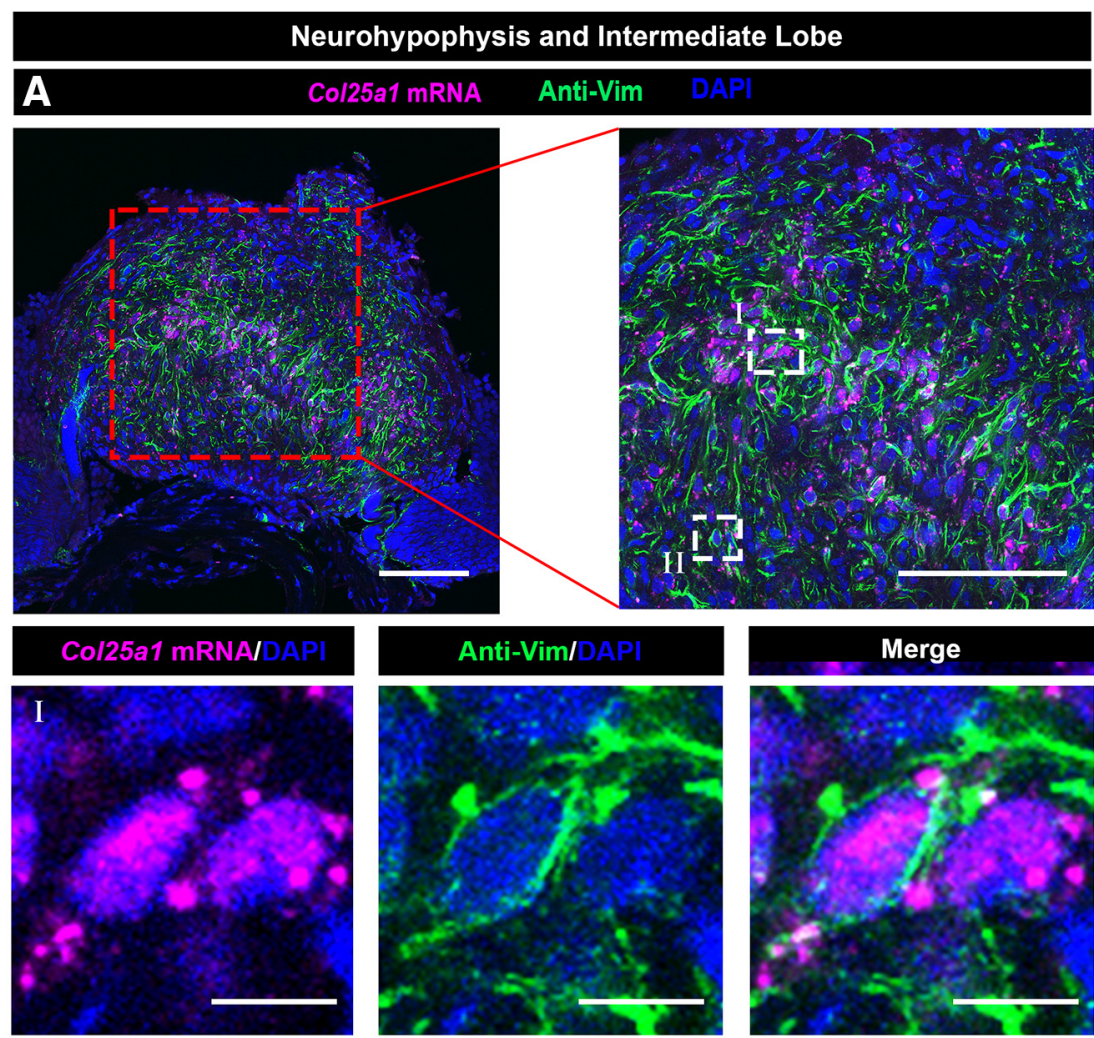

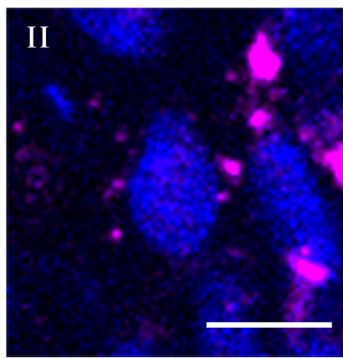

B

\begin{tabular}{|c|c|c|}
\hline Cell population & Mean No. of Cells & Ratio \\
\hline 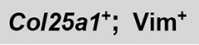 & 22 & $21 \%$ \\
\hline 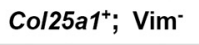 & 23 & $21 \%$ \\
\hline Col25a1 ; $\mathrm{Vim}^{+}$ & 18 & $16 \%$ \\
\hline Col25a1'; Vim & 46 & $43 \%$ \\
\hline
\end{tabular}
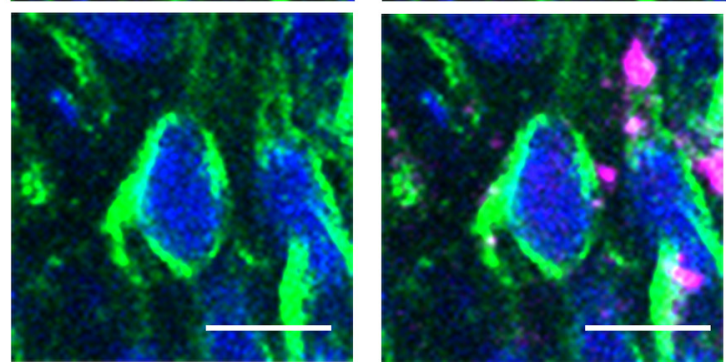

Cell count distribution

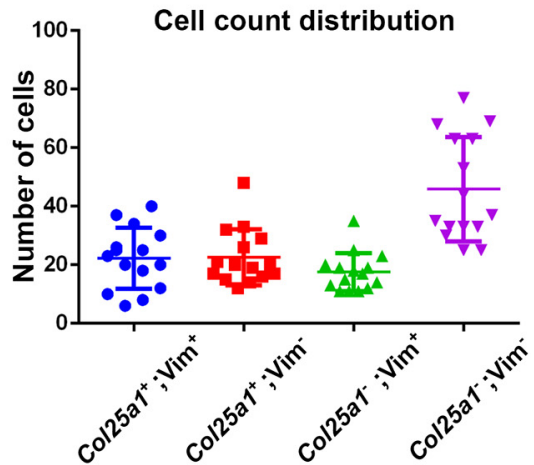

Figure 5. Expression of the novel pituicyte marker Col25a1, in the $\mathrm{NH}$. $\boldsymbol{A}$, Validation of the scRNA-Seq results using wholemount staining of dissected NH derived from a C57/BL6 adult mouse. Dissected NH was subjected to fluorescent mRNA in situ hybridization with an antisense Col25a1 probe, followed by immunostaining with an antibody directed to the Vim protein and visualized by confocal microscopy. The top panels display different magnifications (scale bars, $100 \mu \mathrm{m}$ ) a single confocal optical plane of Col25a1, Vim, and the nuclei dye, DAPI. Highly magnified field (scale bars, $10 \mu \mathrm{m}$ ) of views showing a representative Col25a $1^{+}$; Vim ${ }^{+}$pituicyte $(\mathrm{I})$ and another Col25a1;; Vim ${ }^{+}$neurohypophyseal cell (II). B, Numbers of different subpopulation of cell expressing Col25a1 and/or Vim were analyzed in 15 randomly chosen areas of interest (between 18,133 and 40,429 $\mu \mathrm{m}^{2}$ ). The average cell numbers and ratios, as well as the individual counting in each region of interest, are presented. 


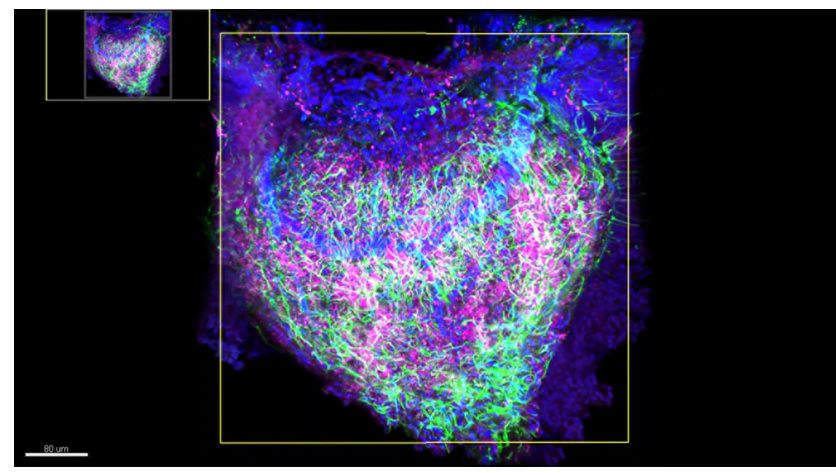

Movie 1. WISH of col25a1 co-stained with Vim antibody and DAPI on dissected NH of three-month-old C57/BL6. [View online]

of the commonly used pituicyte markers also label other $\mathrm{NH}$ cell types.

\section{Spatial organization of neurohypophyseal cell types}

To better understand the spatial organization of neurohypophyseal cell types, we analyzed the expression of selected genetic markers representing the major $\mathrm{NH}$ cell types and localized the expression on a horizontal section of whole mouse pituitary (Fig. 6A). We performed single molecule smFISH on a pituitary derived from a transgenic macrophage/microglia reporter (Fig. 6) as well as wholemount mRNA in situ hybridization combined with antibody staining (Fig. 7). Our scRNA-Seq analysis indicated that Srebf1 is a novel pituicyte marker displaying limited expression in the epithelial-like cells, while Cyp2f2 was highly expressed in epithelial-like cells (Figs. 3, 6B). Accordingly, Srebf1 was prominently expressed in the $\mathrm{NH}$ (Fig. 6B; Extended Data Figs. 6-1, 6-2B), while Cyp2f2expressing cells were mostly located at the boundary between the IL and the AH (Fig. 6B; Extended Data Fig. 6-1). Notably, Cyp2f2 mRNA signals were much weaker in the $\mathrm{NH}$ compared to the IL and the $\mathrm{AH}$ boundary suggesting that some epithelial-like cells are also found in the $\mathrm{NH}$ (Fig. 6B; Extended Data Figs. 6-1, 6-2B). This conclusion was further confirmed using smFISH to probe another specific epithelial-like featured gene, Lcn2, which was mainly expressed by cells located at the $\mathrm{IL}$ and $\mathrm{AH}$ boundary (Extended Data Fig. 6-2B).

We next performed simultaneous labeling of macrophage/microglia, pituicyte, and epithelial-like cells by performing smFISH of Srebf1 and Cyp2f2 probes on pituitaries of transgenic $C \times 3 c r 1$ :GFP reporter mice, labeling macrophage/microglia (Jung et al., 2000). We observed that the Cx3cr1: GFP-positive macrophage/ microglia were distributed throughout the whole pituitary, including the $\mathrm{NH}$, IL, and $\mathrm{AH}$ (Fig. 6B; Extended Data Fig. $6-2 C)$. These macrophages/microglia were intermingled with both Srebf1'; Cyp2f2- pituicytes and Cyp2f2 ${ }^{+}$ epithelial-like cells suggesting a possible cross-talk between pituitary cells and these macrophages/microglia (Fig. 6B).

Our scRNA-Seq analysis also detected an $\mathrm{NH}$ cell population, which co-expressed Pdgfra and Lum (Fig. 2; Extended Data Fig. 1-3). We assumed that this cell pop- ulation is similar or identical to the so-called VLMC, which has been found to localized on blood vessels of the brain (Marques et al., 2016; He et al., 2018; Vanlandewijck et al., 2018). We, therefore, examined the tissue distribution of VLMC cells and fenestrated neurohypophyseal vascular endothelia, which express the Plvap protein (Stan et al., 1999; Gordon et al., 2019). This analysis confirmed that as in the case of brain vasculature, VLMCs were in close association with the fenestrated endothelia of the NH (Fig. 7). Finally, although we have found a small population of T-cell like cells in the $\mathrm{NH}$, immunostaining of the T-cellspecific cell surface marker, $\mathrm{Cd} 3$, revealed low abundance of Cd3-positive cells in the NH (Kindt et al., 2007; Extended Data Fig. 6-2D). It is likely that these T cells are not a resident $\mathrm{NH}$ population but rather a transient population, which is transported from the blood. The above in situ hybridization analyses confirmed our featured gene designation determined by scRNA-Seq.

Taken together, our gene expression analysis of $\mathrm{NH}$ and IL reveals a comprehensive view of neuro-IL cell types in adult male mice. This study provides an important resource for specific functional studies and possible crosstalk between the various $\mathrm{NH}$ cell types.

\section{Discussion}

The $\mathrm{NH}$ is a major neuroendocrine interface, which allows the brain to regulate the function of peripheral organs in response to specific physiologic demands. Despite its importance, a comprehensive molecular description of cell identities in the $\mathrm{NH}$ is still lacking. Recent studies revealed cell heterogeneity of whole pituitary gland using scRNA-Seq, however, these studies did not separate the $\mathrm{NH}$ from the adjacent $\mathrm{AH}$ and very few $\mathrm{NH}$ cells with limited sequence information were reported (Cheung et al., 2018; Ho et al., 2018; Mayran et al., 2018). Here, utilizing scRNA-Seq technology, we identified the transcriptomes of five major neurohypophyseal cell types and two IL cell populations in the adult male mice. Using selected featured genetic markers, we mapped the spatial distribution of selected cell types in situ.

The identified differentially expressed gene clusters revealed by scRNA-Seq correspond to previously characterized cell types. Thus, previous studies reported the appearance of pituicyte (Seyama et al., 1980; Wittkowski, 1986; Yamamoto and Nagy, 1993; Furube et al., 2014; Anbalagan et al., 2018), macrophage/microglia (Pow et al., 1989; Sasaki and Nakazato, 1992; Kindt et al., 2007), and fenestrated endothelia (Gordon et al., 2019) in the $\mathrm{NH}$. The identification of IL and epithelial-like cells in the present study is in agreement with other reports of these cells in the mammalian pituitary (Hudson, 2002; Moran et al., 2011) and also matches recent scRNA-Seq analyses of whole mouse pituitary (Cheung et al., 2018; Ho et al., 2018; Mayran et al., 2018).

The novel pituicyte markers identified in our study showed more specific and robust expression than previously published pituicyte markers. Among them, Srebf1, Col13a1, Adm, Scn7a, and Col25a1 were not reported to be expressed by pituicyte. Vegfa was reported as pituicyte marker in both mice and zebrafish (Furube et al., 


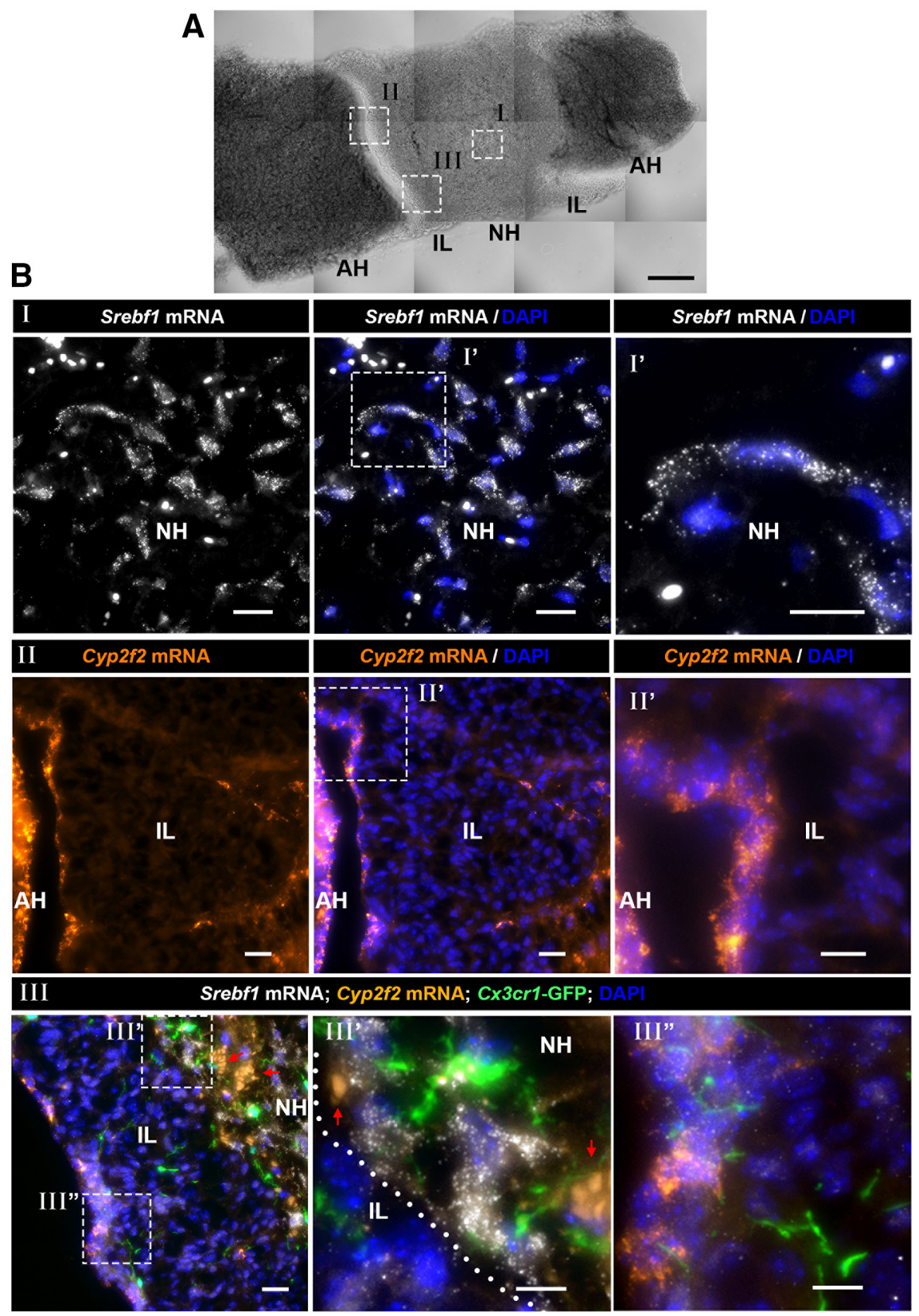

Figure 6. Spatial distribution of pituicyte, macrophage/microglia and epithelial-like cells in the NH and IL. $\boldsymbol{A}$, A brightfield image of a horizontal section of adult mouse pituitary showing the locations of the $\mathrm{NH}$, IL, and $\mathrm{AH}$. The white boxes in the brightfield image mark the locations of specific pituitary subdomains shown in the fluorescent images below (scale bar, $100 \mu \mathrm{m})$. $\boldsymbol{B}$, Different fields of views (marked by roman numbers) of horizontal section $(7 \mu \mathrm{m})$ of pituitaries derived from three-month-old Cx3cr1-GFP macrophage/ microglia transgenic reporter mouse, which were subjected to smFISH with antisense probes directed to Srebf1 (I), Cyp2f2 (II), or multiplexed smFISH of Srebf1 and Cyp2f2 on Cx3cr1:GFP mouse (III) to observe the relative location of selected cell types. A high-magnification image of the region delineated with the white dashed box is shown. White dotted line in III' marks the boundary between IL and $\mathrm{NH}$. Note that the smFISH probe of epithelial-like cell marker, Cyp2f2, labels the border between the IL and the AH, as well as IL cells. Arrows indicate background autofluorescent signals of circulating erythrocytes. Scale bars, $20 \mu \mathrm{m}$ (I, II) and $10 \mu \mathrm{m}$ (III).

2014; Anbalagan et al., 2018). Srebf1 protein is involved in sterol biosynthesis process, this may be relevant to the lipid droplets that were found in ultra-structure studies of pituicyte (Seyama et al., 1980; Wittkowski, 1986; Anbalagan et al., 2018). Other prominent pituicyte markers we identified, such as Rax, Scn7a, Col25a1, and Adm were reported as hypothalamic tanycyte markers (MirandaAngulo et al., 2014; Pak et al., 2014; Campbell et al., 2017; Chen et al., 2017; Franzen et al., 2019). Our finding that Rax, Scn7a, Col25a1, and Adm are expressed in pituicytes is in line with the notion that tanycytes and pituicytes are of a common astrocytic lineage (Wittkowski, 


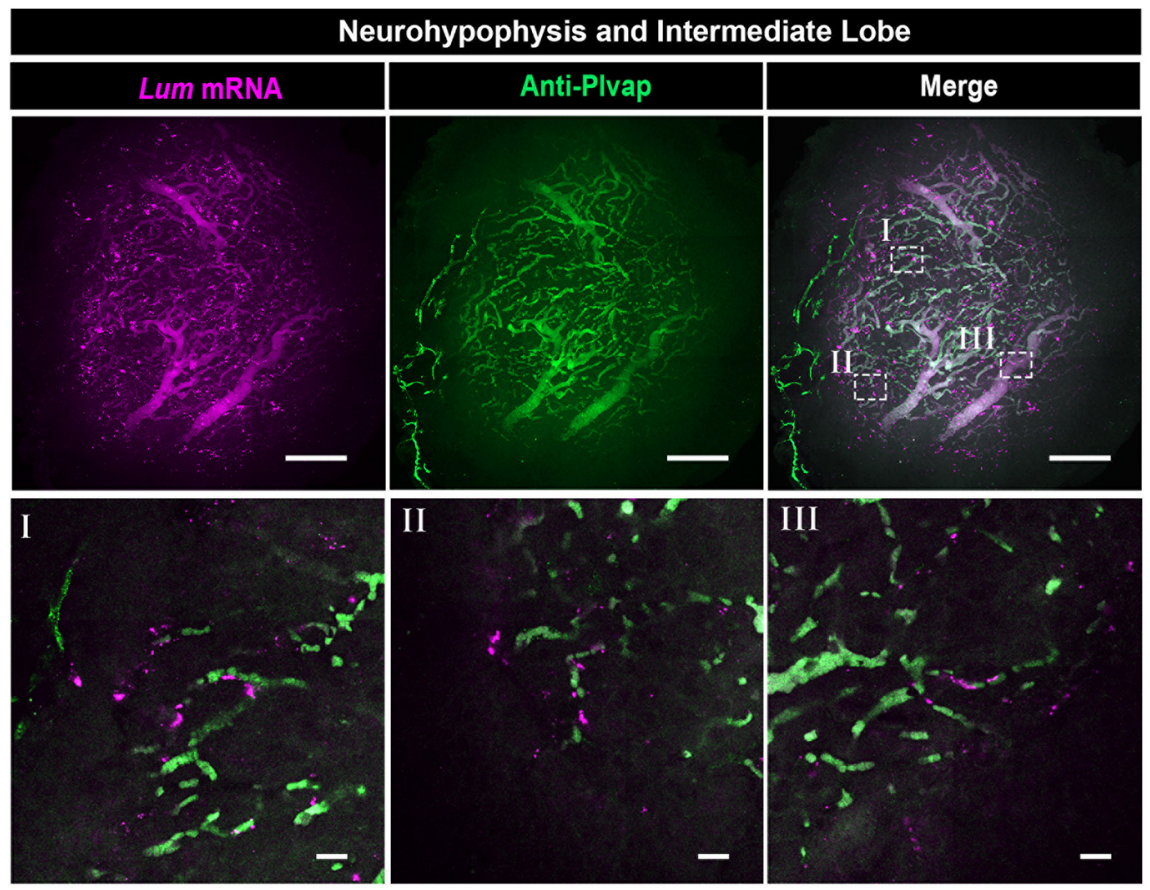

Figure 7. Neurohypophyseal VLMCs are associated with fenestrated vascular endothelia. Confocal Z-stack (maximum intensity projection) of dissected $\mathrm{NH}$, which was subjected to wholemount FISH with an antisense RNA probe directed to the VLMC marker, Lum, followed by immunostaining with an antibody directed to Plvap protein, which is a marker of fenestrated endothelia (scale bars, $100 \mu \mathrm{m}$ ). The bottom panels (labeled I-III) display high-magnification single plane confocal images of the respective regions delineated in white boxes in the top right panel (scale bars, $20 \mu \mathrm{m}$ ).

1998; Clasadonte and Prevot, 2018; Rodríguez et al., 2019). Specifically, Rax is a general tanycyte marker (Campbell et al., 2017; Chen et al., 2017; RodríguezRodríguez et al., 2019), Scn7a, Col25a1, and Adm were reported as $\beta 2$ tanycyte markers (Campbell et al., 2017; Rodríguez-Rodríguez et al., 2019). Finally, Col25a1 was found to be enriched in the $\mathrm{NH}$ according to the Bgee database (Bastian et al., 2008).

Our novel pituicyte markers displayed greater specificity (i.e., adjusted $p \leq 0.05$ for differential expression), higher expression level (average In fold change $\geq 1$ ) and robustness (i.e., abundance in pituicytes) compared to the most commonly used markers. Thus, as we previously showed in the case of zebrafish pituicytes (Anbalagan et al., 2018), we found that Apoe is broadly expressed in multiple mouse $\mathrm{NH}$ cell types. However, although Vim and Gfap displayed relatively low mRNA expression levels in our scRNA-Seq analysis, their protein immunoreactivity was readily detectable in the $\mathrm{NH}$. This could be due to the inherently shallow sequencing method for $10 x$ Genomics platform. The astroglial protein $S 100 \beta$ is also used to label pituicytes (Cocchia, 1981). It was reported that $S 100 \beta$ is highly abundant when compared to $\mathrm{Vim}^{+}$and $\mathrm{Gfap}^{+}$cells (Virard et al., 2008; Wei et al., 2009). However, in our study, $S 100 \beta$ was not among the top differentiallyexpressed pituicyte genes but was found to be exclusively expressed in the VLMC cell type. In view of the gene coverage limitation of the 10x Genomics platform, $S 100 \beta$ might have been missed in our analysis, hence, future studies should be aware of our findings regarding its expression in VLMC. Another known pituicyte-specific marker, namely Gja1, also known as Cx43, displayed robust specific expression in our mouse pituicyte cluster. This is in agreement with the reported findings in rat and zebrafish (Yamamoto and Nagy, 1993; Anbalagan et al., 2018).

We identified VLMC as a new neurohypophyseal cell type which is marked by the prominent expression of Pdgfra and Lum. We further showed that VLMC is associated with $P / v a p^{+}$fenestrated neurohypophyseal capillaries. In agreement with our findings, $\mathrm{Pdgfra}^{+} ; \mathrm{Lum}^{+}$ VLMC population was found in the mouse brain as vascular-associated cell type (Marques et al., 2016) or as fibroblast-like cells that are loosely attached to vessels and located in between smooth muscle cells and astrocyte end-feet (Vanlandewijck et al., 2018). Although VLMC express some markers of oligodendrocyte precursor cells (OPCs), such as Pdgfra, they are distinct from OPCs and oligodendrocyte lineages (Marques et al., 2016).

Importantly, previous reports have described the existence of OPCs in the NH (Virard et al., 2006, 2008; Miyata, 2017). We did not detect OPCs in the present study, however, this could be due to the low abundance of these cells in our tissue. Alternatively, because Virard et al. relied on Pdgfra as a sole OPC marker, it is possible that they misidentified VLMCs as OPCs. Notably, Virard et al. reported that these $\mathrm{Pdgfra}^{+}$cells were shown to be pituicyte progenitors in their study (Virard et al., 2006). Similarly, other studies reported that VLMC display multipotent stem cell niche function in the CNS and other organs suggesting that they may play similar roles in $\mathrm{NH}$ function (Nakagomi and Matsuyama, 2017; Ueharu et al., 
2018). Further studies are required to determine whether neurohypophyseal OPCs are in fact VLMCs and whether VLMCs are pituicyte progenitors.

Although pericytes have been previously reported to be associated with neurohypophyseal capillaries (Miyata, 2017; Nishikawa et al., 2017), we did not detect them in the present study, possibly due to the fact that isolating pericytes requires different tissue dissociation conditions. It is also possible that other minor neurohypophyseal cell populations have been missed, which may be revealed if more cells would be sampled.

Macrophage/microglia were found in our study as prominent $\mathrm{NH}$ resident cells. Previous reports showed that neurohypophyseal microglia in rat endocytose and digest axonal terminus (Pow et al., 1989), whereas the pituicyte envelops the buttons of axons (Morris, 1976) and provide cues for the permeable endothelial fate (Anbalagan et al., 2018). Our finding that macrophage/microglia are closely located to the pituicytes in the $\mathrm{NH}$ is in agreement with such functional cooperation between these two cell types.

In summary, our transcriptome analysis of individual cells derived from $\mathrm{NH}$ and IL tissues of adult male mice have revealed the cellular heterogenicity of the $\mathrm{NH}$ and provide novel molecular markers for the major cells in those tissues. We present a valuable resource that will serve as the basis for further functional studies.

\section{References}

Anbalagan S, Gordon L, Blechman J, Matsuoka RL, Rajamannar P, Wircer E, Biran J, Reuveny A, Leshkowitz D, Stainier DYR, Levkowitz G (2018) Pituicyte cues regulate the development of permeable neuro-vascular interfaces. Dev Cell 47:711-726.

Bastian F, Parmentier G, Roux J, Moretti S, Laudet V, RobinsonRechavi M (2008). Bgee: integrating and comparing heterogeneous transcriptome data among species. In: Data integration in the life sciences (Bairoch A, Cohen-Boulakia S, Froidevaux C, eds), pp 124-131. Berlin, Heidelberg: Springer.

Benjamini Y, Hochberg Y (1995) Controlling the false discovery rate: a practical and powerful approach to multiple testing. J R Stat Soc Ser B 57:289-300.

Boyle El, Weng S, Gollub J, Jin H, Botstein D, Cherry JM, Sherlock G (2004) GO::TermFinder--ppen source software for accessing Gene Ontology information and finding significantly enriched Gene Ontology terms associated with a list of genes. Bioinformatics 20:3710-3715.

Boyles JK, Pitas RE, Wilson E, Mahley RW, Taylor JM (1985) Apolipoprotein $\mathrm{E}$ associated with astrocytic glia of the central nervous system and with nonmyelinating glia of the peripheral nervous system. J Clin Invest 76:1501-1513.

Bucy PC (1930) The pars nervosa of the bovine hypophysis. J Comp Neurol 50:505-519.

Butler A, Hoffman P, Smibert P, Papalexi E, Satija R (2018) Integrating single-cell transcriptomic data across different conditions, technologies, and species. Nat Biotechnol 36:411-420.

Campbell JN, Macosko EZ, Fenselau H, Pers TH, Lyubetskaya A, Tenen D, Goldman M, Verstegen AMJ, Resch JM, McCarroll SA, Rosen ED, Lowell BB, Tsai LT (2017) A molecular census of arcuate hypothalamus and median eminence cell types. Nat Neurosci 20:484-496.

Chen R, Wu X, Jiang L, Zhang Y, Zhang Y (2017) Single-cell RNA-seq reveals hypothalamic cell diversity. Cell Rep 18:3227-3241.

Cheung LYM, George AS, McGee SR, Daly AZ, Brinkmeier ML, Ellsworth BS, Camper SA (2018) Single-cell RNA sequencing re- veals novel markers of male pituitary stem cells and hormoneproducing cell-types. Endocrinology 159:3910-3924.

Clasadonte J, Prevot V (2018) The special relationship: glia-neuron interactions in the neuroendocrine hypothalamus. Nat Rev Endocrinol 14:25-44.

Cocchia D (1981) Immunocytochemical localization of S-100 protein in the brain of adult rat. Cell Tissue Res 214:529-540.

Dellmann HD, Sikora K (1981) Pituicyte fine structure in the developing neural lobe of the rat. Dev Neurosci 4:89-97.

Dieck ST (1999) The peptide transporter PepT2 is expressed in rat brain and mediates the accumulation of the fluorescent dipeptide derivative beta-Ala-Lys-N-AMCA in astrocytes. Glia 25:10-20.

Donadon MF, Martin-Santos R, Osório FL (2018) The associations between oxytocin and trauma in humans: a systematic review. Front Pharmacol 9:154.

Franzen O, Gan L, Björkegren JLM (2019) PanglaoDB: a web server for exploration of mouse and human single-cell RNA. Database 2019:1-9.

Furube E, Mannari T, Morita S, Nishikawa K, Yoshida A, Itoh M, Miyata S (2014) VEGF-dependent and PDGF-dependent dynamic neurovascular reconstruction in the neurohypophysis of adult mice. J Endocrinol 222:161-179.

Gordon L, Blechman J, Shimoni E, Gur D, Anand-Apte B, Levkowitz G (2019) Fenestrae-associated protein Plvap regulates the rate of blood-borne proteins passage into the hypophysis. Development 146:dev177790.

Gutnick A, Blechman J, Kaslin J, Herwig L, Belting H-G, Affolter M, Bonkowsky JL, Levkowitz G (2011) The hypothalamic neuropeptide oxytocin is required for formation of the neurovascular interface of the pituitary. Dev Cell 21:642-654.

Hatton GI (1988) Pituicytes, glia and control of terminal secretion. J Exp Biol 139:67-79.

He L, Vanlandewijck M, Mäe MA, Andrae J, Ando K, Del Gaudio F, Nahar K, Lebouvier T, Laviña B, Gouveia L, Sun Y, Raschperger E, Segerstolpe Å, Liu J, Gustafsson S, Räsänen M, Zarb Y, Mochizuki N, Keller A, Lendahl U, et al. (2018) Single-cell RNA sequencing of mouse brain and lung vascular and vessel-associated cell types. Sci Data 5:180160.

Hindmarch C, Yao S, Beighton G, Paton J, Murphy D (2006) A comprehensive description of the transcriptome of the hypothalamoneurohypophyseal system in euhydrated and dehydrated rats. Proc Natl Acad Sci USA 103:1609-1614.

Ho Y, Hu P, Peel MT, Camara PG, Wu H, Liebhaber SA (2018) Single cell transcriptomic analysis of the adult mouse pituitary reveals a novel multi-hormone cell cluster and physiologic demand-induced lineage plasticity. bioRxiv 475558 .

Hudson DL (2002) Keratins as markers of epithelial cells. In: Epithelial cell culture protocols (Wise C, ed), pp 157-167. Totowa, NJ: Humana Press.

Ji N, van Oudenaarden A (2012) Single molecule fluorescent in situ hybridization (smFISH) of C. elegans worms and embryos. WormBook, ed. The C.elegans Research Community, WormBook. Available at http://doi.org/10.1895/wormbook.1.153.1.

Jung S, Aliberti J, Graemmel P, Sunshine MJ, Kreutzberg GW, Sher A, Littman DANR (2000) Analysis of fractalkine receptor $C_{3}$ CR1 Function by targeted deletion and green fluorescent protein reporter gene insertion. Mol Cell Biol 20:4106-4114.

Kachitvichyanukul V, Schmeiser B (1985) Computer generation of hypergeometric random variates. J Stat Comput Simul 22:127145.

Kindt TJ, Goldsby RA, Osborne BA, Kuby J (2007) Kuby immunology. New York: W.H. Freeman.

Larkin S, Ansorge O (2017) Development and microscopic anatomy of the pituitary gland. In: Endotext (De Groot L, Chrousos G, Dungan K, eds), p 2000. South Dartmouth, MA: MDText.com, Inc.

Lee HJ, Macbeth AH, Pagani JH, Scott Young W (2009) Oxytocin: the great facilitator of life. Prog Neurobiol 88:127-151.

Liss L (1958) The Nature of the so-called Herring Bodies. J Neural Transm 17:301-307. 
Liu C, Shao ZM, Zhang L, Beatty P, Sartippour M, Lane T, Livingston E, Nguyen M (2001) Human endomucin is an endothelial marker. Biochem Biophys Res Commun 288:129-136.

Machluf Y, Levkowitz G (2011) Visualization of mRNA expression in the zebrafish embryo. In: RNA detection and visualization: methods and protocols (Gerst JE, ed), pp 83-102. Totowa, NJ: Humana Press.

Marin F, Boya J, Lopez-Carbonell A (1989) Immunocytochemical localization of vimentin in the posterior lobe of the cat, rabbit and rat pituitary glands. Acta Anat (Basel) 134:184-190.

Marques S, Zeisel A, Codeluppi S, Bruggen D. Van Falcão AM, Xiao L, Li H, Häring M, Hochgerner H, Romanov RA, Gyllborg D, Muñoz Manchado A, La Manno G, Lönnerberg P, Floriddia EM, Rezayee F, Ernfors P, Arenas E, Hjerling-Leffler J, Harkany T, et al. (2016) Oligodendrocyte heterogeneity in the mouse juvenile and adult central nervous system. Science 352:1326-1329.

Mayran A, Sochodolsky K, Khetchoumian K, Harris J, Gauthier Y, Bemmo A, Balsalobre A, Drouin J (2018) Pioneer and nonpioneer factor cooperation drives lineage specific chromatin opening. bioRxiv 472647.

Miranda-Angulo AL, Byerly MS, Mesa J, Wang H, Blackshaw S (2014) Rax regulates hypothalamic tanycyte differentiation and barrier function in mice. J Comp Neurol 522:876-899.

Miyata S (2017) Advances in understanding of structural reorganization in the hypothalamic neurosecretory system. Front Endocrinol (Lausanne) 8:275.

Moran TB, Goldberg LB, Serviss SL, Raetzman LT (2011) Numb deletion in POMC-expressing cells impairs pituitary intermediate lobe cell adhesion, progenitor cell localization, and neurointermediate lobe boundary formation. Mol Endocrinol 25:117127.

Morris J (1976) Distribution of neurosecretory granules among the anatomical compartments of the neurosecretory processes of the pituitary gland: a quantitative ultrastructural approach to hormone storage in the neural lobe. J Endocrinol 68:225-234.

Murphy D, Konopacka A, Hindmarch C, Paton JF, Sweedler JV, Gillette MU, Ueta Y, Grinevich V, Lozic M, Japundzic-Zigon N (2012) The hypothalamo-neurohypophyseal system: from genome to physiology. J Endocrinol 24:539-553.

Nakagomi T, Matsuyama T (2017) Leptomeninges: a novel stem cell niche with neurogenic potential. Stem Cell Investig 4:22.

Nishikawa K, Furube E, Morita S, Horii-Hayashi N, Nishi M, Miyata S (2017) Structural reconstruction of the perivascular space in the adult mouse neurohypophysis during an osmotic stimulation. $J$ Neuroendocrinol 29.

Norris DO, Carr JA, Norris DO, Carr JA (2013). The hypothalamuspituitary system in non-mammalian vertebrates. In: Vertebrate endocrinology, pp 151-205. San Diego: Academic Press.

Olazábal DE (2018) Role of oxytocin in parental behaviour. J Neuroendocrinol 30:1-13.

Pak T, Yoo S, Miranda-Angulo AM, Wang H, Blackshaw S (2014) Rax-CreERT2 knock-in mice: a tool for selective and conditional gene deletion in progenitor cells and radial glia of the retina and hypothalamus. PLoS One 9:1-13.

Potter SS (2018) Single-cell RNA sequencing for the study of development, physiology and disease. Nat Rev Nephrol 14:479-492.

Pow DV, Perry VH, Morris JF, Gordon S (1989) Microglia in the neurohypophysis associate with and endocytose terminal portions of neurosecretory neurons. Neuroscience 33:567-578.

Robinson AG, Verbalis JG (2003) The posterior pituitary gland. In: Williams textbook of endocrinology (Larson P, Kronengerg $\mathrm{H}$,
Melmed S, Polonsky K, eds), pp 281-330. Philadelphia: WB Saunders.

Rodríguez-Rodríguez A, Lazcano I, Sánchez-Jaramillo E, Uribe RM, Jaimes-Hoy L, Joseph-Bravo P, Charli JL (2019) Tanycytes and the control of thyrotropin-releasing hormone flux into portal capillaries. Front Endocrinol (Lausanne) 10:401.

Rodríguez E, Guerra M, Peruzzo B, Blázquez JL (2019) Tanycytes: a rich morphological history to underpin future molecular and physiological investigations. J Neuroendocrinol 31:e12690.

Sasaki A, Nakazato Y (1992) The identity of cells expressing MHC class II antigens in normal and pathological human brain. Neuropathol Appl Neurobiol 18:13-26.

Saunders A, Macosko EZ, Wysoker A, Goldman M, Krienen FM, de Rivera H, Bien E, Baum M, Bortolin L, Wang S, Goeva A, Nemesh J, Kamitaki N, Brumbaugh S, Kulp D, McCarroll SA (2018) Molecular diversity and specializations among the cells of the adult mouse brain. Cell 174:1015-1030.

Seyama S, Pearl GS, Takei Y (1980) Ultrastructural study of the human neurohypophysis. Cell Tissue Res 206:291-302.

Stan R-V, Kubitza M, Palade GE (1999) PV-1 is a component of the fenestral and stomatal diaphragms in fenestrated endothelia. Proc Natl Acad Sci USA 96:13203-13207.

Suess U, Pliška V (1981) Identification of the pituicytes as astroglial cells by indirect immunofluorescence-staining for the glial fibrillary acidic protein. Brain Res 221:27-33.

Ueharu H, Yoshida S, Kanno N, Horiguchi K (2018) SOX10-positive cells emerge in the rat pituitary gland during late embryogenesis and start to express S100 $\beta$. Cell Tissue Res 372:77-90.

Vanlandewijck M, He L, Mäe MA, Andrae J, Ando K, Del Gaudio F, Nahar K, Lebouvier T, Laviña B, Gouveia L, Sun Y, Raschperger E, Räsänen M, Zarb Y, Mochizuki N, Keller A, Lendahl U, Betsholtz C (2018) A molecular atlas of cell types and zonation in the brain vasculature. Nature 554:475-480.

Virard I, Coquillat D, Bancila M, Kaing S, Durbec P (2006) Oligodendrocyte precursor cells generate pituicytes in vivo during neurohypophysis development. Glia 303:294-303.

Virard I, Gubkina O, Alfonsi F, Durbec P (2008) Characterization of heterogeneous glial cell populations involved in dehydrationinduced proliferation in the adult rat neurohypophysis. Neuroscience 151:82-91.

Wei XY, Zhao CH, Liu YY, Wang YZ, Ju G (2009) Immuohistochemical markers for pituicyte. Neurosci Lett 465:27-30.

Wircer E, Ben-Dor S, Levkowitz G (2016) Non-mammalian models for neurohypophysial peptides. Mol Neuroendocrinol 301-328.

Wircer E, Blechman J, Borodovsky N, Tsoory M, Nunes AR, Oliveira RF, Levkowitz G (2017) Homeodomain protein otp affects developmental neuropeptide switching in oxytocin neurons associated with a long-term effect on social behavior. Elife 6:e22170.

Wittkowski W (1986) Pituicytes. Astrocytes 1:173-208.

Wittkowski W (1998) Tanycytes and pituicytes: morphological and functional aspects of neuroglial interaction. Microsc Res Tech 41:29-42.

Yamamoto T, Nagy JI (1993) Connexin43 in rat pituitary: localization at pituicyte and stellate cell gap junctions and within gonadotrophs. Histochemistry 100:53-64.

Zeisel $A$, Hochgerner $H$, Lönnerberg $P$, Johnsson $A$, Memic $F$, van der Zwan J, Häring M, Braun E, Borm LE, La Manno G, Codeluppi S, Furlan A, Lee K, Skene N, Harris KD, Hjerling-Leffler J, Arenas E, Ernfors P, Marklund U, Linnarsson S (2018) Molecular architecture of the mouse nervous system. Cell 174:999-1014. 